\title{
Bipolar catheter electrograms for study of retrograde atrial activation pattern in patients without pre-excitation syndromes
}

\author{
A. S. Agha, B. Befeler, A. M. Castellanos, R. J. Sung, C. A. Castillo, R. J. Myerburg, \\ and A. Castellanos \\ From the Division of Cardiology, Department of Medicine, University of Miami School of Medicine and \\ the Cardiovascular Laboratories, Veterans Administration Hospital and Fackson Memorial Hospital, \\ Miami, Florida, U.S.A.
}

The sequence of retrograde atrial activation of premature ventricular beats was studied in 12 patients without pre-excitation syndrome. Forward and retrograde $A V$ nodal conduction times were within normal limits. The septal low right atrial ( $L R A_{2}$ ) deflection was inscribed 25 to $55 \mathrm{~ms}$ (ave: $37.9 \mathrm{~ms}$ ) before the low left atrial $\left(L L A_{2}\right)$ electrogram and 35 to $75 \mathrm{~ms}$ (ave: $53.7 \mathrm{~ms}$ ) ahead of the high right atrial (HRA $\left.A_{2}\right)$ deflection. $L L A_{2}$ preceded $H R A_{2}$ in 8 patients, more or less coincided with $H R A_{2}$ in 3 cases, and was inscribed 10 ms ahead in 1 patient. In all cases a decrease in the coupling $\left(S t_{1}-S t_{2}\right)$ interval resulted in a proportional increase of the septal $L R A_{1}-L R A_{2}, L L A_{1}-L L A_{2}$, and $H R A_{1}-H R A_{2}$ intervals. Atrial echoes occurring in 3 cases had a sequence of arrival of excitation at the recording sites which was similar to the ones shown by the same patients during ventricular pacing. This is in keeping with the existence of an upper common pathway located above the area where functional longitudinal dissociation occurred.

Thus, it is concluded that impulses emerging from the $A V$ node in a retrograde direction reach the septal low right atrium before they activate the explored low left atrial sites, regardless as to whether they arise in the ventricles or in the atria.

There have been several reports in which the sequence of atrial activation during retrograde (VA) conduction through accessory pathways has been discussed (Latour and Puech, 1957; Torresani et al., 1969, Grolleau et al., 1970; Spurrell, Krikler, and Sowton, 1974b; Svenson et al., 1975; Gallagher et al., 1975; Tonkin et al., 1975a, b). In contrast, few studies have dealt with the usefulness of right and left atrial electrograms in analysing the pattern of atrial activation of impulses reaching the atria retrogradely through the AV node in patients without pre-excitation syndrome (Nicolai et al., 1970; Castellanos, Castillo, and Myerburg, 1971b; Svenson et al., 1974; Gallagher et al., 1975; Wu et al., 1975).

\section{Subjects and methods}

The technique used in our department for analysis of the electrical activity of the His bundle and several atrial sites has been discussed previously Received 25 November 1975.
(Castellanos et al., 1971b; Agha et al., 1972; Castellanos et al., 1972). After explaining the procedure and obtaining consent three tripolar catheter electrodes were introduced to obtain bipolar electrograms from the vicinity of the AV node in the septal low right atrium (LRA), $1 \mathrm{~mm}$ and/or $11 \mathrm{~mm}$ apart, as recorded by the His bundle electrographic lead (HBE); from the high right atrium (HRA) close to the superior vena cava, and from the low left atrium (LLA) explored through the coronary sinus in a position from which electrical stimulation produced negative $P$ waves in leads I, II, and III (Agha et al., 1972). In 4 cases, 2 HBE leads (with interelectrode distances of 1 and $11 \mathrm{~mm}$, respectively) were recorded at the same time (Fig. 1). Filtered $40-500$ or $400-500 \mathrm{~Hz}$ intracardiac electrograms were obtained simultaneously, with at least three surface leads at a paper speed of $100 \mathrm{~mm} / \mathrm{s}$.

The moment of arrival of excitation at the recording electrodes (considered to have occurred at the 


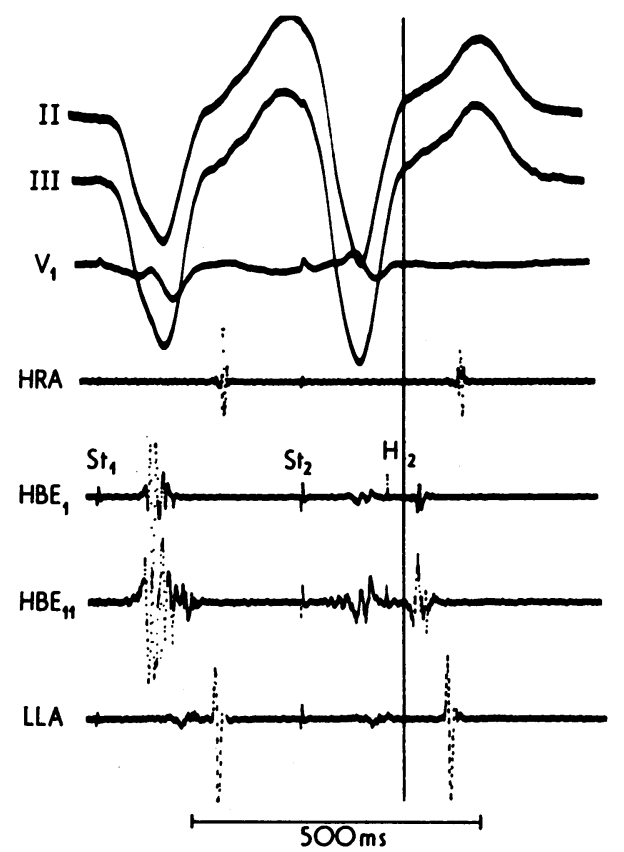

F I G. 1 Arrival of excitation at the recording atrial sites during retrograde (VA) conduction through the $A V$ node-His Purkinje system. HRA=high right atrium; $H B E_{1}$ and $H B E_{11}=$ electrograms 1 and 11 mm apart recorded by the His bundle electrographic leads. $L L A=$ low left atrium. St $t_{1}=d r i v i n g$ stimuli. $S t_{2}=$ testing stimulus. The onset of the corresponding atrial electrograms was as follows: (1) low septal right atrium in $H B E_{1} ;$ (2) low septal right atrium in $H B E_{11}$; (3) $L L A$; and (4) $H R A$. This was more evident after $S_{2} t_{2}$ because the corresponding deflections were farther apart from the $Q R S$ complex.

onset of the corresponding electrograms) was studied during sinus rhythm as well as during atrial and ventricular pacing with the extrastimulus method in 12 patients with (presumably) chronic conducting disease who showed retrograde (VA) conduction during ventricular pacing. The latter was a prerequisite for this study. Retrograde activation of the atria was considered to have been present when the sinus sequence of arrival of excitation (HRA to septal LRA) changed to a septal LRA to HRA sequence. Spontaneous or induced runs of tachycardia were not seen in these patients.

Because not all retrograde His bundle and septal LRA deflections could be identified in driven beats, the time elapsing between inscription of the corresponding electrograms was measured following premature beats with coupling intervals short enough to allow the retrograde $\mathrm{H}_{2}$ deflections to emerge after the end of the ventricular electrograms (Castillo and Castellanos, 1970).

The following nomenclature will be used in this report:

$A, H$, and $V$ represent the onset of septal LRA, His bundle, and ventricular deflections in the HBE during sinus rhythm.

HRA $_{1}, H_{2} A_{2}$, septal LRA , septal LRA LLA $_{1}$ LLA $_{2}, \mathrm{H}_{1}$, and $\mathrm{H}_{2}$ are the electrograms in the corresponding sites produced by driving $\left(\mathrm{St}_{1}\right)$ and testing $\left(\mathrm{St}_{2}\right)$ impulses. $\mathrm{HBE}_{1}$ and $\mathrm{HBE}_{11}$ refer to the interelectrode distances with which these leads were recorded.

\section{Results}

During sinus rhythm the duration of the $\mathrm{AH}$ intervals was normal according to the values presently used in our laboratory ( 60 to $120 \mathrm{~ms}$ ). The sequence of arrival of excitation was from HRA to septal LRA to LLA. A similar sequence was observed when the HRA was paced.

Since this was a prerequisite in this study, retrograde (VA) conduction was seen in all patients during right ventricular apical pacing with the extrastimulus method. Retrograde AV nodal conduction time (given by the retrograde $\mathrm{H}_{2}$-septal $\mathrm{LRA}_{2}$ interval) was normal (between 70 and $110 \mathrm{~ms}$, Table). The septal $\mathrm{LRA}_{2}$ deflection was inscribed 25 to $55 \mathrm{~ms}$ (average $37.9 \mathrm{~ms}$ ) before LLA $_{2}$ and 35 to $75 \mathrm{~ms}$ (average $53.7 \mathrm{~ms}$ ) before $\mathrm{HRA}_{2}$ (Table, Fig. 1 and 2). The LLA $_{2}$ electrogram preceded

T A B L E Differences in arrival of excitation at recording sites during retrograde atrial activation (in $\mathrm{ms}$ )

\begin{tabular}{lllll}
\hline Case No. & $\begin{array}{l}H_{2-}- \\
L R A_{2}\end{array}$ & $\begin{array}{l}L R A_{2-} \\
L L A_{2}\end{array}$ & $\begin{array}{l}L R A_{2-} \\
H R A_{2}\end{array}$ & $\begin{array}{l}L L A_{2^{-}} \\
H R A_{2}\end{array}$ \\
\hline 1 & 90 & 25 & 75 & 50 \\
(atrial echo) & - & 25 & 75 & 50 \\
2 & 85 & 35 & 55 & 20 \\
(atrial echo) & - & 35 & 55 & 0 \\
3 & 85 & 55 & 55 & 0 \\
(atrial echo) & - & 55 & 55 & 0 \\
4 & 110 & 30 & 60 & 30 \\
5 & 95 & 25 & 55 & 25 \\
6 & 105 & 30 & 40 & 10 \\
7 & 110 & 35 & 35 & 0 \\
8 & 105 & 40 & 70 & 30 \\
9 & 70 & 50 & 70 & 20 \\
10 & 95 & 40 & 40 & 0 \\
11 & 90 & 50 & 40 & -10 \\
12 & 85 & 40 & 50 & 10 \\
\hline Average & 93.7 & 37.9 & 53.7 & $15 \cdot 4$ \\
\hline
\end{tabular}


HRA $_{2}$ in 8 patients, occurred at more or less the same time in 3 patients, and was inscribed $10 \mathrm{~ms}$ later in 1 case. The morphology of the $P$ waves in the standard leads could not be determined with certainty since on most occasions they appeared on top of the $T$ waves.

In all cases a decrease in the coupling $\left(\mathrm{St}_{1}-\mathrm{St}_{2}\right)$ interval was associated with an increase of the septal LRA 1 -LRA ${ }_{2}, \mathrm{LLA}_{1}-\mathrm{LLA}_{2}$, and HRA ${ }_{1}-\mathrm{HRA}_{2}$ intervals which was of the same order of magnitude. As mentioned previously, retrograde activation of the His bundle was seen at the shorter coupling intervals in all patients but the $\mathrm{H}_{1}-\mathrm{H}_{2}$ intervals could not be measured because $\mathrm{H}_{1}$ was frequently buried within the ventricular electrogram of the HBE lead.

Although runs of tachycardia were not elicited in the patients studied, single atrial echoes were induced by premature atrial stimulation in three cases (Table). When this occurred the sequence of arrival of excitation at the recording atrial sites was similar to the one shown by the same patients during ventricular pacing (Fig. 2 and 3).

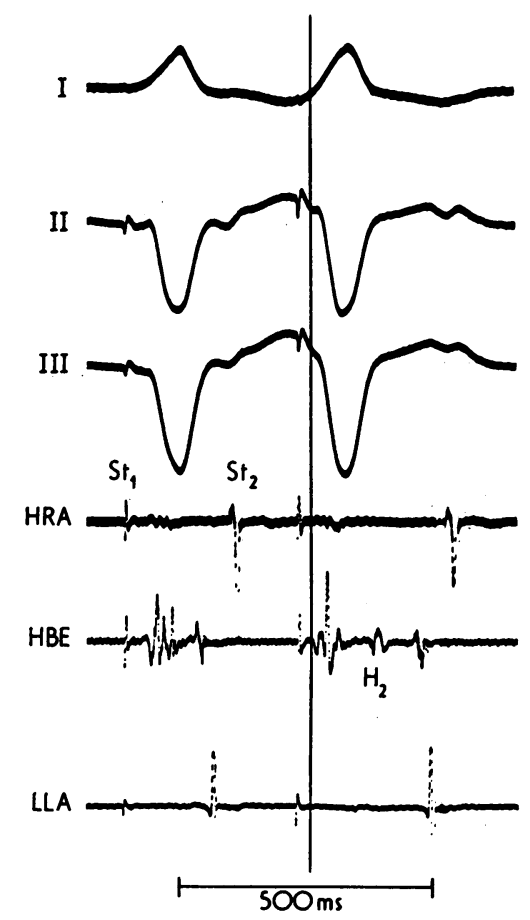

F I G. 2 Arrival of excitation at the recording sites during retrograde ( $V A$ ) conduction following driving and premature stimuli.

\section{Discussion}

Recent studies have shown that some symptomatic patients with Wolff-Parkinson-White (WPW) syndrome might have unidirectional antegrade block in the accessory pathway, the latter being able to conduct exclusively in a retrograde direction (Slama, Coumel, and Bouvrain, 1973; Spurrell, Krikler, and Sowton, 1974a; Wellens and Durrer, 1974; Coumel and Attuel, 1974; Narula, 1974; Neuss, Schlepper, and Thormann, 1975; Svenson et al., 1975; Tonkin et al., 1975a, b).

Since intractable recurrent AV tachycardia can occur in these cases, surgical modes of therapy have been developed. Thus, identification of the accessory pathways which are functionally silent during antegrade conduction is of clinical importance. However, to accomplish this an understanding of the normal sequence of retrograde atrial activation is necessary.

The results of the present study show that in the absence of pre-excitation, activation of the septal LRA in the vicinity of the AV node (as recorded by the HBE lead) preceded that of the LLA (as recorded from the coronary sinus) and, of course, that of the HRA (Table, Fig. 1 and 2).

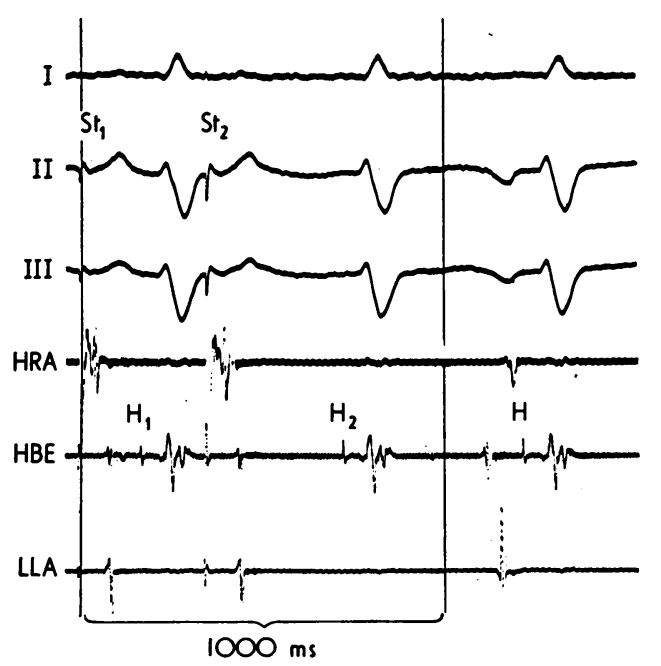

FIG. 3 (Same patient as in Fig. 2.) Arrival of excitation at the recording sites during driving $\left(S t_{1}\right)$ and testing ( $\left(\mathrm{St}_{2}\right)$ impulses delivered to the HRA and after an (atrial) echo induced by the second atrial impulse. The sequence of retrograde atrial activation of the echo was similar to that seen in the same patient during ventricular pacing (Fig. 2). 
Moreover, in the 3 patients with atrial echo beats (elicited by premature atrial stimulation) the sequence of arrival of excitation at the recording electrodes was similar to that occurring in the same cases during the retrograde atrial activation of premature ventricular beats (Table and Fig. 2 and 3). Thus, it seems that the retrograde AV nodal-atrial pathway used by the returning impulse was the same in both situations. This is in keeping with the presence of a common 'upper pathway' located above the site where functional longitudinal dissociation of the AV node occurs (Scherf and Shookhoff, 1926; Schamroth, 1971). However, a larger number of patients should be studied to determine whether this is seen in all cases as well as in patients with accessory atrio-AV nodal or atrioHis bundle pathways.

It should be stressed that the differences in arrival of excitation at different sites are subjected to several variables that might explain the range of values shown in the Table. Foremost among these is the inevitability of some degree of catheter movement during the procedure (Agha et al., 1972). Even with great care it is possible, if the procedure is prolonged or the patient is not fully co-operative, for the electrode to shift its position from the beginning to the end of the procedure. In our department this happened more often with the HRA electrode (Agha et al., 1972). In retrospect, this factor might explain why in Case 11 (Table) the LLA $_{2}$ electrogram was inscribed $10 \mathrm{~ms}$ after that of $\mathrm{HRA}_{2}$. Yet, the possibility of conduction through a preferential intra-atrial pathway (though less likely) cannot be completely excluded. A useful suggestion would be to compare radiographic films obtained at the beginning and at the end of the strip, which was not done in this study.

Furthermore, the coronary sinus electrode might not have been in an equivalent position in all of our cases. For instance, Tonkin et al. (1975b) and Svenson et al. (1975) have recorded several simultaneous electrograms from within the coronary sinus in patients with parietal left ventricular accessory pathways. They observed that the proximal coronary sinus to septal LRA intervals were shorter than distal coronary sinus to septal LRA intervals.

Another factor which has to be considered in evaluating differences shown in the Table is given by the method of recording electrograms as well as by the moment in which arrival of excitation at the electrodes as believed to have occurred. In some of our cases in which two HBE leads were recorded, the onset of retrograde bipolar atrial electrograms $1 \mathrm{~mm}$ apart occurred 15 to $20 \mathrm{~ms}$ after that of bipolar electrograms $11 \mathrm{~mm}$ apart, even when recorded simultaneously through the same catheter
(Fig. 1). These differences can also be noted during sinus rhythm since the inscription of the atrial electrograms $1 \mathrm{~mm}$ apart occurred after that of the electrograms $11 \mathrm{~mm}$ apart (Fig. 4).

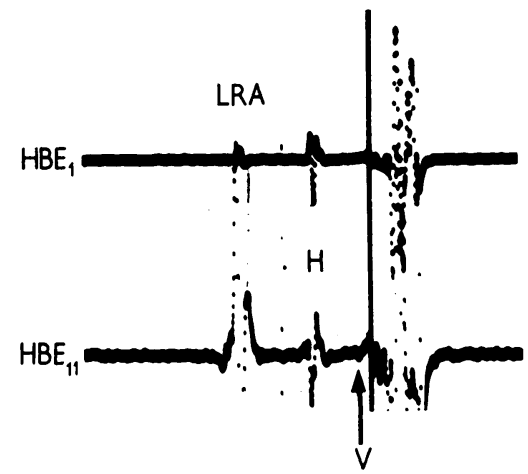

F I G. 4 Magnification of the onset of septal low right atrial (LRA) deflections in $H B E_{1}$ and $H B E_{11}$ during sinus rhythm. Note that the atrial electrograms recorded by the former start with the rapid deflections of the electrogram recorded with electrodes $11 \mathrm{~mm}$ apart. Thus, the corresponding $A H$ interval had a shorter duration.

That is, the $\mathrm{AH}$ intervals were shorter and the $\mathrm{H}_{2}-\mathrm{A}_{2}$ intervals were longer when electrodes $1 \mathrm{~mm}$ apart were used. This might explain why Akhtar et al. (1975), who used electrodes $10 \mathrm{~mm}$ apart, recorded shorter $\mathrm{H}_{2}-\mathrm{A}_{2}$ intervals (range 15 to 45; average $37.9 \mathrm{~ms}$ ) than those observed in this study. However, the possibility of retrograde conduction through an antegradely blocked accessory atrio-His pathway could not be excluded in the cases of Akhtar et al. This raises the question as to whether patients with overt atrio-His pathways in whom both AV and VA conduction occurs via the bypass tract have a retrograde atrial activation pattern similar to that shown in Fig. 1 and 2.

In spite of this critical analysis, catheter recordings can be used to differentiate between the retrograde atrial activation pattern of impulses emerging from the AV node and that of those reaching the atria through a left sided (parietal) accessory pathway (WPW Type A). Yet, ectopic atrial impulses originating close to the area where the accessory pathway enters the left atrium could give a similar (in respect of catheter recordings) retrograde activation sequence. This can be seen in Fig. 83 of the monograph by Latour and Puech (1957) and in Fig. 6 of the article by Castellanos et al. (1971a). 


\section{References}

Agha, A. S., Castillo, C. A., Castellanos, A., Jr., Myerburg, R. J., and Tessler, M. P. (1972). Supernormal conduction in the human atria. Circulation, 46, 522.

Akhtar, M., Damato, A. N., Batsford, W. P., Ruskin, J. N., and Ogunkelu, J. B. (1975). A comparative analysis of antegrade and retrograde conduction patterns in man. Circulation, 52, 766.

Castellanos, A., Jr., Castillo, C. A., Agha, A. S., and Tessler, (1971a). His bundle electrograms in patients with short P-R intervals, narrow QRS complexes, and paroxysmal tachycardias. Circulation, 43, 667.

Castellanos, A., Jr., Castillo, C. A., and Myerburg, R. J. (1971b). Bipolar coronary sinus lead for left atrial and left vertricular recording. American Heart fournal, 81, 832.

Castellanos, A., Jr., Iyengar, R., Agha, A. S., and Castillo, C. A. (1972). Wenckebach phenomenon within the atria. British Heart fournal, 34, 1121.

Castillo, C. A., and Castellanos, A., Jr. (1970). Retrograde activation of the His bundle during intermittent paired ventricular stimulation in the human heart. Circulation, 42, 1079.

Coumel, P., and Attuel, P. (1974). Reciprocating tachycardia in overt and latent preexcitation. European fournal of Cardiology, 1, 423.

Gallagher, J. J., Gilbert, M., Svenson, R. H., Sealy, W. C., Kasell, J., and Wallace, A. G. (1975). Wolff-ParkinsonWhite syndrome: the problem, evaluation, and surgical correction. Circulation, 51, 767.

Grolleau, R., Dufoix, R., Puech, P., and Latour, H. (1970). Les tachycardies par rhythme réciproque dans le syndrome de Wolff-Parkinson-White. Archives des Maladies du Coeur et des Vaisseaux, 63, 74.

Latour, H., and Puech, P. (1957). Electrocardiographie Endocavitaire, p. 255. Massor, Paris.

Narula, O. S. (1974). Retrograde pre-excitation: comparison of antegrade and retrograde conduction intervals in man. Circulation, 50, 1129.

Neuss, H., Schlepper, M., and Thormann, J. (1975). Analysis of re-entry mechanisms in three patients with concealed Wolff-Parkinson-White syndrome. Circulation, 51, 75.

Nicolai, P., Delaage, M., Medvedowsky, J. L., Arnoux, M., and Jouve, A. (1970). Conduction auriculaire rétrograde permanente en cours de tachycardie ventriculaire. Archives des Maladies du Coeur et des Vaisseaux, 63, 1057.

Schamroth, L. (1971). The Disorders of Cardiac Rhythm, p. 224. Blackwell, Oxford.

Scherf, D., and Shookhoff, C. (1926). Experimentelle Untersuchungen über die 'Umkehr-Extrasystole' (reciprocating beat). Wiener Archiv für innere Medizin, 12, 501.
Slama, P. R., Coumel, P., and Bou rrain, Y. (1973). Les syndromes de Wolff-Parkinson-White de type $A$ innapparents ou latents en rhythm sinusal. Archives des Maladies $d u$ Coeur et des Vaisseaux, 66, 639.

Spurrell, R. A. J., Krikler, D. M., and Sowton, E. (1974a). Concealed bypasses of the atrioventricular node in patients with paroxysmal supraventricular tachycardia revealed by intracardiac stimulation and Verapamil. American fournal of Cardiology, 33, 590.

Spurrell, R. A. J., Krikler, D. M., and Sowton, E. (1974b). Two anomalous atrioventricular connections in patients with the Wolff Parkinson White syndrome. American Fournal of Cardiology, 33, 171.

Svenson, R. H., Gallagher, J. J., Sealy, W. C., and Wallace, A. G. (1974). An electrophysiologic approach to the surgical treatment of the Wolff-Parkinson-White syndrome. Report of two cases utilizing catheter recording and epicardial mapping techniques. Circulation, 49, 799.

Svenson, R. H., Miller, H. C., Gallagher, J. J., and Wallace, A. G. (1975). Electrophysiological evaluation of the Wolff-Parkinson-White syndrome: problems in assessing antegrade and retrograde conduction over the accessory pathway. Circulation, 52, 552.

Tonkin, A. N., Gallagher, J. J., Svenson, R. H., Wallace, A. G., and Sealy, W. C. (1975a). Anterograde block in accessory pathways with retrograde conduction in reciprocating tachycardia. European fournal of Cardiology, 3, 143.

Tonkin, A. N., Miller, H. C., Svenson, R. H., Wallace, A. G., and Gallagher, J. J. (1975b). Refractory periods of the accessory pathway in Wolff-Parkinson-White syndrome. Circulation, 52, 563.

Torresani, J., Amichot, J. L., Picard, J. P., and Jouve, A. (1969). Acquisitions récentes daus les techniques d' exploration electrocardiographique des cavités cardiaques. Archives des Maladies du Coeur et des Vaisseaux, 62, 193.

Wellens, H. J. J., and Durrer, D. (1974). Patterns of ventriculo-atrial conduction in the Wolff-Parkinson-White syndrome. Circulation, 49, 22.

Wu, D., Denes, P., Wyndham, C., Amat-y-Leon, F., Dhingra, R. C., and Rosen, K. M. (1975). Demonstration of dual atrioventricular nodal pathways utilizing a ventricular extrastimulus in patients with atrioventricular nodal reentrant paroxysmal supraventricular tachycardia. Circulation, 52, 789.

Requests for reprints to Professor Agustin Castellanos, Division of Cardiology, University of Miami School of Medicine, P.O. Box 520875, Miami, Florida 33152, U.S.A. 